\title{
Harmonized bionomenclature - a recipe for disharmony
}

\author{
A. E. Orchard ${ }^{1}$, W. R. Anderson ${ }^{2}$, M. G. Gilbert ${ }^{3}$, Sebsebe D. ${ }^{4}$, W. T. Stearn ${ }^{5}$ \& E. G. \\ Voss $^{2}$
}

Many taxonomists, from both the botanical and zoological sides of the fence, will have been startled to find that proposals are well advanced to change radically the way in which they practice their science.

Hawksworth (1995) has provided a synopsis of steps towards the writing and possible adoption of a unified International code of bionomenclature, arising from a number of small workshops held in the years between 1985 and 1994. His mandate for doing this was the establishment of a Special Committee on Harmonization of the Codes, set up after minimal discussion at the nomenclature sessions of the International Botanical Congress in Yokohama in 1993.

It arose out of a proposal by Hawksworth (1993) to alter Art. 65 of the Berlin Code to extend the consideration of homonymy of generic names beyond the botanical Code. In coining new generic names botanists were to include consideration of the Approved List of Bacterial Names and any zoological names on proposed future Lists of Names in Use accorded special protected status by the International Commission on Zoological Nomenclature. This proposal was heavily rejected in the postal ballot prior to the Yokohama congress, but was resurrected at the formal meeting.

The brief discussion revealed that the major concerns in raising the matter were twofold: the problem experienced by some taxonomists in having to differentiate between identical generic names legitimately in use for both plant and animal groups under the botanical and zoological Codes, and the problems experienced by those working in some protist groups where organisms can legitimately bear two correct names, depending on whether one decides to treat them as plants or animals.

The Special Committee on Harmonization of the Codes was set up with the mandate "to investigate all borderline problems between the biological Codes, and the special problems of all borderline groups, and eventually all questions of harmonization of the Codes that were felt to be soluble" (Greuter \& al., 1994: 193). Most of those present at the meeting where this Committee was established presumably believed that they were voting on a mechanism to bring the Codes closer together in relatively minor matters where disruption to existing names and practices would be minimal. At no time was it suggested that the process would involve complete scrapping of the existing Codes and the writing of a new "Harmonized Code" involving elements of all of them.

Throughout the process since 1985 there has been little attempt to involve the general botanical taxonomic community (the practitioners who have to make the Code work) in a discussion of the benefits and costs of such a "harmonization"

\footnotetext{
1 Australian Biological Resources Study, G.P.O. Box 636, Canberra ACT 2601, Australia.

${ }^{2}$ University of Michigan Herbarium, North University Building, Ann Arbor, MI 48109-1057, U.S.A.

${ }^{3}$ Botany Department, Natural History Museum, London SW7 5BD, U.K.

${ }^{4}$ National Herbarium, Science Faculty, Addis Abeba University, P.O. Box 3434, Addis Abeba, Ethiopia.

517 High Park Road, Kew, Richmond, Surrey TW9 3AB, U.K.
} 
exercise. Such matters may have been discussed at the various meetings summarized by Hawksworth, but these involved only a handful of people. The general community of taxonomists was, and is, completely unaware that moves are afoot to change the face of nomenclatural practice in the next 5 years.

A draft Code has now been compiled and is circulating amongst the IAPT nomenclatural committees. In addition there are two booklets published by IUBS, Towards a harmonized bionomenclature for life on earth (Hawksworth \& al., 1994) and $A$ draft glossary of terms used in bionomenclature (Hawksworth, 1994). All of these publications assume that a Code of bionomenclature will become a reality within a few years.

For botanists, the changes proposed will be substantial. Familiar terms such as "effectively published", "validly published", "legitimate" and "correct" will be replaced by their zoological equivalents, or by new terms. Zoologists are well-advanced in discussions on the abolition of gender in generic names, and the maintenance of the original adjectival form of epithets upon transfer. It has been suggested that this idea be extended to botanical names. The present requirement in botany that new names must be accompanied by a Latin description or diagnosis would be changed to require either a Latin or English description or diagnosis. In the case of transfers of epithets, the citation of the transferring author (non-parenthetical author) would become optional. The new Code relies very heavily on the acceptance of lists of protected names (until now called Names in Current Use in botany), and indeed it is difficult to see how it could function without them. The concept of lists of Names in Current Use with special protected status was rejected at the Yokohama Congress, and although it will be raised again in St Louis in 1999, there is no guarantee that it will be accepted.

An even more foreign concept to botanists will be the proposal to adopt the zoological convention on co-ordinate status of names. In this system epithets have priority (and are automatically generated) for a range of taxonomic ranks simultaneously. Thus names in the "species group" will have the same priority at ranks of species and subspecies simultaneously, names in the "genus group" at both genus and subgenus rank, and in the "family group" at all ranks between superfamily and subtribe. Currently in the botanical Code epithets or names have priority only in a single rank. Publication (formerly "effective publication") will be allowed on microcards, microfiches and non-erasable laser discs, but not by distribution of films or photographs of text or images (the difference in treatment of microfiche and film is not explained).

Several of these changes were proposed at the Yokohama Congress, and rejected, some overwhelmingly. For example, the dual use of Latin or English for diagnoses was decisively rejected both in the postal vote and in the floor vote. Names in Current Use were narrowly defeated. Expansion of the media allowed for effective publication was referred to a Special Committee.

Despite the major changes proposed in the "harmonized Code" proposal, almost all of them a consequence of trying to merge irreconcilable differences between the standard procedures adopted by botanists and zoologists, and enshrined in their current Codes, at least one of the two core problems identified by Hawksworth remains. Generic homonyms across kingdoms coined before the new starting point (proposed as 1 January 2000) would be protected, and would remain to confuse users and 
provide noise in databases. The other problem, confusion over which Code applied to some protist groups, would be eliminated.

However, a basic question seems not to have been asked. Can a less disruptive solution be found to address these two problems? We believe that there are several possible answers, of which the following are the least unsettling to current practice.

Two-kingdom generic homonyms. - The problems of the past probably cannot be entirely eliminated without major disruption to existing nomenclature, unacceptable to most users. Some specific cases might be eliminated by use of existing mechanisms for conservation and rejection of names, where little-used or synonymized names might be removed from the system on a case-by-case basis. The Tokyo Code has greatly strengthened conservation and rejection powers, and these should be given time to work. For the future, it is certainly possible to prevent the coining of new cross-kingdom generic homonyms by simply inserting in the existing botanical and zoological Codes new Articles (Rules) that outlaw the practice. The bacteriological Code already forbids the creation of new names for bacteria that "are junior homonym[s] of a name of a taxon of bacteria, fungi, algae, protozoa or viruses". For this to be effective, up-to-date lists of existing generic names across all kingdoms will need to be readily available. It is believed that this might be a reality by the turn of the century.

Names of protist groups. - It is claimed that the names of around 30,000 taxa of protists are currently subject to uncertainty, many having two correct names under the competing Codes. However, to reorganize and rewrite Codes governing perhaps tens of millions of organisms to accommodate 30,000 seems heavy handed to say the least. Despite increasing evidence that the organisms traditionally treated as "fungi" and "algae" probably constitute several kingdoms, and that some of these at least are more closely allied to the traditional animals than to the plants, the inclusion of provisions for their nomenclature within the botanical Code is a pragmatic solution that, on the whole, works well. The Codes should not be viewed as a definitive statement on phylogeny. They are simply a set of rules to govern the way names are manipulated.

Consequently the "problem" of the protists should be amenable to a very simple solution - arbitrarily assign each major group to one or the other of the two main Codes and rule that that Code will be the one governing their nomenclature. Both existing major Codes already have provision for special rules for certain groups of organisms if necessary (the botanical Code for instance has special provisions for fossils and fungi). Thus the dinoflagellates might be ruled to be governed by the botanical Code. This does not imply that they are henceforth ruled to be plants, only that this is the set of rules which will govern their nomenclature. It is to be anticipated that some argument will ensue over whether, e.g., the dinoflagellates are more "plant-like" than "animal-like" and therefore which way they should go, but in the end, does it really matter? If the designations of major groups referred to above are chosen at a high enough level (e.g. division or phylum) then there should usually be little doubt as to which Code applies to which organisms. For those organisms that are subsequently removed from one division to another on the basis of a reassessment of their properties, and hence to another Code (surely a relatively tiny number), a rule stating that their names have priority only within their original Code should suffice to prevent established names being overturned. 
Most of our botanical taxonomic colleagues are satisfied with the way the present botanical Code works in the vast majority of cases. Similarly, zoologists of our acquaintance are in general satisfied with the way their Code serves their needs. The botanical Code has been honed and polished over a hundred or more years, to become a very sophisticated instrument in the hands of skilled practitioners. Non-taxonomists may well complain that it is too complex, but then, for the most part they are not required to use it. In arguments about satisfying end-users it seems to be forgotten often that these end-users use only the end product of taxonomy. It is unreasonable to demand that a computer should be constructed on such simple principles that anyone with a spanner and screwdriver can fix it. The inner workings of computers are necessarily complex, and best left to the professionals who understand them. The rest of us just need to be able to manipulate the keyboard and mouse. Similarly any attempt to simplify the workings of nomenclatural Codes will almost inevitably lead to destruction of the intricate checks and balances painstakingly built into them over many Congresses and many years. The end result will be a lowest common denominator Code that will work less satisfactorily than the present ones, and may in fact not work at all. At the very least, the process of fine tuning will need to begin again, absorbing massive amounts of time from some of our leading taxonomists.

The haste with which this proposal is being advanced is of particular concern. The botanical Code (and the other Codes) derive their authority only from a consensus of practicing taxonomists or nomenclaturalists. In the past a lack of consensus has led to competing Codes being adopted in different parts of the world (for example, the American Code of a century ago). It is not inconceivable that similar splits could develop again, if taxonomists feel that a major change is being imposed upon them. Changes of the magnitude of the proposed International code of bionomenclature and related Names in Current Use will require considerable discussion and consultation before and during several Congresses if they are to attract consensus support. However, we would argue that far simpler solutions to the perceived problems are available, and would be far more readily accepted by the constituency.

With taxonomy in crisis in most countries of the world, with an aging and shrinking population of trained taxonomists being called upon to provide more and more information faster and faster as the threats to world biodiversity mount daily, why are we now embarking on such a massively disruptive exercise? The world desperately needs more quality taxonomic work, not a bureaucratic "tidying up" of the nomenclatural system to distract our best minds from their primary task. The proponents of the International code of bionomenclature and Names in Current Use will need to provide far more compelling arguments than they have to date, before we are convinced that a shakeup of nomenclatural procedures, which rivals that of Linnaeus in 1753 , is more than a distraction that we can well do without.

\section{Literature cited}

Greuter, W., McNeill, J. \& Barrie, F. R. 1994. Report on botanical nomenclature - Yokohama 1993. Englera 14: 1-265.

Hawksworth, D. L. 1993. (245-259) Fifteen miscellaneous proposals towards the evolution of a Code appropriate to the needs of the 21st century. Taxon 42: 156-162.

- 1994. A draft glossary of terms used in bionomenclature. IUBS Monogr. 9: 1-74.

- 1995. Steps along the road to a harmonized bionomenclature. Taxon 44: 447-456.

- , McNeill, J., Sneath, P. H. A., Trehane, R. P. \& Tubbs, P. K. 1994. Towards a harmonized bionomenclature for life on Earth. Biol. Int., Special Issue 30: 1-44. 